CLINICAL STUDY

\title{
Plasma 25-hydroxyvitamin D, 1,25-dihydroxyvitamin D, and parathyroid hormone in familial hypocalciuric hypercalcemia and primary hyperparathyroidism
}

Signe Engkjær Christensen ${ }^{1}$, Peter H Nissen ${ }^{2}$, Peter Vestergaard ${ }^{1}$, Lene Heickendorff ${ }^{2}$, Lars Rejnmark ${ }^{1}$, Kim Brixen ${ }^{3}$ and Leif Mosekilde ${ }^{1}$

Departments of ${ }^{1}$ Endocrinology and Metabolism C and ${ }^{2}$ Clinical Biochemistry, Aarhus University Hospital, Aarhus Sygehus, Tage-Hansens gade 2 , DK 8000 Århus C, Denmark and ${ }^{3}$ Department of Endocrinology, Odense University Hospital, Odense, Denmark

(Correspondence should be addressed to S E Christensen; Email: rlg06sec@as.aaa.dk)

\begin{abstract}
Introduction: Familial hypocalciuric hypercalcemia $(\mathrm{FHH})$ is a lifelong, benign, inherited condition caused by inactivating mutations in the calcium-sensing receptor (CASR) gene. Both FHH and primary hyperparathyroidism (PHPT) are characterized by elevated P-calcium, normal or elevated plasmaparathyroid hormone (P-PTH), and typically normal renal function. In PHPT, vitamin D metabolism is typically characterized by low plasma levels of 25-hydroxyvitamin D (250HD), and high plasma levels of 1,25-dihydroxyvitamin $\mathrm{D}\left(1,25(\mathrm{OH})_{2} \mathrm{D}\right)$. In $\mathrm{FHH}$, the vitamin $\mathrm{D}$ metabolism is not very well known. Objective: To compare and evaluate plasma $25 \mathrm{OHD}, 1,25(\mathrm{OH})_{2} \mathrm{D}$, and PTH in FHH and PHPT. Design: Cross-sectional study.

Materials: About $66 \mathrm{FHH}$ patients with mutations in the CASR gene, 147 patients with surgically verified PHPT, and 46 controls matched to FHH patients according to age ( \pm 5 years), sex, and season. All patients had a P-creatinine $<140 \mu \mathrm{mol} / \mathrm{l}$.

Methods: We measured P-calcium, P-Ca ${ }^{2+}, \mathrm{P}$-albumin, P-creatinine, P-phosphate, P-magnesium, and P-PTH by standard laboratory methods. P-250HD and P-1,25(OH) $)_{2} \mathrm{D}$ were measured by RIA or enzyme immunoassay. In $\mathrm{FHH}$, all protein-coding exons in the CASR gene were sequenced and aligned to GenBank reference sequence NM_000388.2.

Results: PHPT patients had higher body mass index $(2 p<0.01)$, together with higher P-PTH $(2 p<$ $0.01)$ and $\mathrm{P}-1,25(\mathrm{OH})_{2} \mathrm{D}(2 p<0.01)$ compared with $\mathrm{FHH}$ patients. The groups had similar levels of $\mathrm{P}_{-} \mathrm{Ca}^{2+}$ and of $\mathrm{P}-25 \mathrm{OHD}$. The phenotypic expression of the CASR mutations (as determined by the degree of hypercalcemia) did not influence the levels of $\mathrm{P}-1,25(\mathrm{OH})_{2} \mathrm{D}$.

Conclusion: Even though P-calcium and P-25OHD were comparable, P-1,25(OH) ${ }_{2} \mathrm{D}$ and P-PTH differed between FHH and PHPT.
\end{abstract}

European Journal of Endocrinology 159 719-727

\section{Introduction}

Familial hypocalciuric hypercalcemia (FHH, OMIM\# 145980) is an autosomal dominant condition caused by heterozygous, inactivating mutations in the calciumsensing receptor $(C A S R)$ gene $(1,2)$. The CASR regulates blood calcium levels within a narrow range. It is located on the cell membrane of many different cells, but regulates plasma calcium homeostasis mainly through its expression in the parathyroid glands and the kidney tubules (3). At least 64 inactivating mutations have previously been described in the CASR gene (4). With respect to the present population of $\mathrm{FHH}$ patients, we have recently described 22 inactivating mutations, of which 19 were previously unpublished (5).

FHH and primary hyperparathyroidism (PHPT) are characterized by elevated plasma calcium, normal or elevated plasma-parathyroid hormone (P-PTH), and typically normal renal function. The complexity of vitamin D metabolism in PHPT has previously been described in detail (6-8). In short, plasma 25-hydroxyvitamin D (250HD) is characteristically reduced independently of season, sex, or age (6). The excess PTH and the hypophosphatemia increase the renal production of 1,25 dihydroxyvitamin $\mathrm{D}\left(1,25(\mathrm{OH})_{2} \mathrm{D}\right)(7)$. This effect appears to be mitigated by the hypercalcemia $(9,10)$ and possibly by increased plasma levels of fibroblast growth factor-23 (FGF23) $(11,12)$. The increase in $1,25(\mathrm{OH})_{2}$ D levels will per se enhance the inactivation of $250 \mathrm{HD}$ and 1 , $25(\mathrm{OH})_{2} \mathrm{D}$ through renal 24-hydroxylation (9). The hypercalcemia and the elevated plasma $1,25(\mathrm{OH})_{2} \mathrm{D}$ levels could reduce dermal vitamin D production through effects on keratinocytes and melanocytes $(13,14)$. Whether the effects of plasma $\mathrm{Ca}^{2+}$ on dermal cells and renal $1 \alpha$-hydroxylase are mediated via the CASR is at present unknown. The increased body mass index (BMI) 
in PHPT (15) may contribute to a reduction in plasma $25 \mathrm{OHD}$ and $1,25(\mathrm{OH})_{2} \mathrm{D}$ (16). Finally, a pre-existing vitamin D insufficiency could theoretically predispose to the development of PHPT (6). Vitamin D metabolism has been explored only in a small number of $\mathrm{FHH}$ patients (17-19). We have recently reported on the ability of the calcium/creatinine clearance ratio (CCCR) and other variables of renal calcium excretion to discriminate between FHH and PHPT (20), as described by Marx et al. and others $(1,21-26)$.

The aims of the present study:

a) To describe vitamin D metabolites in $\mathrm{FHH}$ compared with normal reference levels and healthy controls.

b) To explore relations between vitamin D metabolites and other clinical variables in FHH.

c) To compare vitamin D metabolites and plasma PTH levels in FHH with the levels in PHPT.

\section{Design}

We used a cross-sectional design. All patients were subjected to a standardized series of investigations (20). In PHPT, the diagnostic gold standard was histopathological findings at neck exploration leading to normocalcemia 2 months after surgery. In FHH patients, the diagnostic gold standard was the confirmation of a clinically significant mutation (i.e., resulting in hypercalcemia) in the CASR gene $(5,20)$. The more frequent polymorphisms, which may also be found in normocalcemic individuals, are not considered in this study (5).

\section{Patients and materials}

The study was carried out at $56^{\circ} \mathrm{N}$ and covered all seasons apart from September for $\mathrm{FHH}$ patients. From August 2003 to June 2007, we included 66 FHH patients (44 females and 22 males, aged 17-83 years) from 25 kindreds. One $\mathrm{FHH}$ patient had one parathyroid gland removed by surgery, and continued to be hypercalcemic. We compared the FHH patients with 147 hypercalcemic PHPT patients (116 females and 31 males, aged 13-86 years) diagnosed by neck surgery between April 2003 and February 2007. All PHPT patients had elevated or high normal plasma PTH. The upper third of the normal reference range was included, since plasma PTH depends on the vitamin D status in the reference population (27, 28). After parathyroid surgery, histopathological examination revealed adenoma(s) in 119 of the patients, hyperplasia in 26 , and combined adenoma and hyperplasia in 2 patients.

Exclusion criteria for both patient groups included reduced renal function (plasma creatinine $>140 \mu \mathrm{mol} / \mathrm{l}$ ), other calcium-metabolic or bone diseases, lithium treatment, systemic glucocorticoid treatment for more than 6 months, malignant disease, uncontrolled or newly diagnosed chronic disease, and hospital admission due to drug or alcohol abuse.

As normal controls for vitamin D metabolites, we used baseline data from healthy men and postmenopausal women randomly selected from the local background population and used in previous physiological studies carried out between 1998 and 2002 (29-31). Normal subjects with illnesses or medications known to affect bone mineral metabolism (including hormone replacement therapy, diuretics, and pharmacological doses of calcium and vitamin D supplements) were excluded. Other biochemical variables were compared with our normal laboratory reference values.

We could match 46 of the normal controls to the $\mathrm{FHH}$ patients according to age ( \pm 5 years), sex, and season (summer/winter).

The study was approved by the Regional Ethical Committee (Aarhus County \#20030195). All patients with $\mathrm{FHH}$ gave informed verbal and written consent. The database was approved by the Danish Data Protection Agency.

\section{Methods}

\section{Biochemistry}

We measured plasma and urine calcium, plasma $\mathrm{Ca}^{2+}$, albumin, creatinine, and phosphate by standard laboratory methods. We corrected total plasma calcium for individual variations in albumin using the equation: adjusted plasma calcium $(\mathrm{mmol} / \mathrm{l})=$ plasma calcium total $(\mathrm{mmol} / \mathrm{l})+0.00086 \times(650$-plasma albumin $(\mu \mathrm{mol} / \mathrm{l}))$. We measured plasma intact PTH using the Elecsys 2010 immunoassay (Roche Diagnostics). The inter- and intra-assay coefficients of variation $(\mathrm{CV})$ were less than 6 and $2 \%$ respectively.

We measured plasma $250 \mathrm{HD}$ by enzyme immunoassay (IDS, Phoenix, AZ, USA). The intra- and inter-assay CV were 5-7\% (concentration level: $39-165 \mathrm{nmol} / \mathrm{l}$ ) and 5-9\% (concentration level: 40-132 nmol/l) respectively. However, in our normal controls, 25-OHD was measured using an equilibrium RIA (DiaSorin Inc., Stillwater, MN, USA) with inter- and intra-assay CV values of 13 and $10 \%$ respectively. In order to be comparable with the IDS method, the DiaSorin results were adjusted by the formula: $Y(\mathrm{nmol} / \mathrm{l})=1.23 X(\mathrm{nmol} / \mathrm{l})+4.7$ based on double measurements in 123 patients (32).

We measured plasma $1,25(\mathrm{OH})_{2} \mathrm{D}$ by RIA (IDS) with the intra- and inter-assay $\mathrm{CV}$ from 9 to $11 \%$ (concentration level: $37-113 \mathrm{pmol} / \mathrm{l}$ ) and 10 to $14 \%$ (concentration level: $21-135 \mathrm{pmol} / \mathrm{l}$ ) respectively.

In our normal controls, we measured plasma $1,25(\mathrm{OH})_{2} \mathrm{D}$ by the RIA (Nichols Institute, San Clemente, CA, USA) with inter- and intra-assay CV values, both of $11 \%$. In order to be comparable with the IDS method, the Nichols results were adjusted by the formula: $Y$ 
$(\mathrm{pmol} / \mathrm{l})=1.138 X(\mathrm{pmol} / \mathrm{l})+3.9$, based on double measurements in 74 patients (32). We constructed normal 95\% confidence intervals for these variables.

The CCCR was calculated as: $\mathrm{CCCR}=(24 \mathrm{~h}-\mathrm{U}-$ calcium/P-calcium, total $) /(24 \mathrm{~h}-\mathrm{U}$-creatinine/P-creatinine) with variables entered as mmol or $\mathrm{mmol} / \mathrm{l}$.

All analyses were performed in non-fasting individuals.

\section{Genetics}

We characterized $\mathrm{FHH}$ patients by molecular genetic analysis of the CASR gene. This method has previously been described in detail (5). Briefly, all exons, including a minimum of $10 \mathrm{bp}$ of flanking intron sequence, were sequenced directly following PCR and clean-up of PCR products, using BigDye Terminator chemistry (Applied Biosystems, Foster City, CA, USA). Sequences were aligned to GenBank reference sequence NM_000388.2. Findings were confirmed in a second analysis on separately drawn blood. The CASR mutations in the present $\mathrm{FHH}$ group have previously been published $(5,20)$.

\section{Statistical analysis}

We expressed basic variables by their median and range, or mean \pm s.D. We assessed between group differences in means by $t$-test after logarithmic conversion when necessary. Differences between frequencies were assessed by Fisher's exact test. We used multiple linear regressions to adjust for covariates with a significance level for entry of $P \leq 0.05$, and for removal of $P>0.10$. Adjusted values were compared using the F-test. Statistical comparisons that included inter-mutation variation were performed using the one-way ANOVA. Statistical analyses were performed with SPSS version 15.0 software (SPSS Inc., Chicago, IL, USA). All $P$ values mentioned in this paper are two-sided, and the cut-off value of significance is 0.05 .

\section{Results}

\section{FHH patients: baseline characteristics}

The clinical characteristics of the $66 \mathrm{FHH}$ patients are described in detail in Table 1 and compared with normal reference values. All were hypercalcemic, 15 (23\%) had elevated P-PTH, and $16(24 \%)$ had reduced plasma phosphate. A total of $52(93 \%)$ had a renal calcium excretion $<7 \mathrm{mmol} / 24 \mathrm{~h}$. The CCCR varied between 0.002 and $0.026($ mean $=0.008)$. There were no larger abnormalities in plasma creatinine (P-creatinine $<140 \mu \mathrm{mol} / \mathrm{l})$ or creatinine clearance rate. Plasma levels of $25 \mathrm{OHD}$ and $1,25(\mathrm{OH})_{2} \mathrm{D}$ metabolites were mostly within reference limits for normal sex-, age-, and season-matched controls. The 250HD did not differ statistically between the matched FHH $(N=46)$ and controls $(N=46), 2 p=0.37$. The matched FHH group $(\mathrm{N}=46)$ had a significantly higher level of $1,25(\mathrm{OH})_{2} \mathrm{D}$ $(131 \pm 45$ (s.D.), pmol/l) than the controls (mean $=93 \pm$ 40 (s.D.), pmol/l), $2 p<0.01$. In 54 out of the $66 \mathrm{FHH}$ patients, the baseline characteristics have previously been published (20).

Table 1 Clinical characteristics of 66 patients with familial hypocalciuric hypercalcemia. Biochemical values are compared with normal laboratory reference values.

\begin{tabular}{|c|c|c|c|c|}
\hline FHH & $N$ & Median (range) or $\%$ & $\begin{array}{l}\text { 95\% Reference } \\
\text { values }\end{array}$ & $\begin{array}{c}\text { No. of subjects with values outside } \\
95 \% \text { reference values }\end{array}$ \\
\hline Age (years) & 66 & $50(17-83)$ & & \\
\hline Females (\%) & 66 & 66.7 & & \\
\hline Height (m) & 66 & $1.68(1.52-1.90)$ & & \\
\hline Body weight $(\mathrm{kg})$ & 66 & $68.8(50.1-134.5)$ & & \\
\hline BMI $\left(\mathrm{kg} / \mathrm{m}^{2}\right)$ & 66 & $23.8(18.2-39.3)$ & & \\
\hline P-Calcium ionized $(\mathrm{mmol} / \mathrm{l})$ & 66 & $1.41(1.32-1.70)$ & $1.15-1.30$ & 66 [i] \\
\hline P-Calcium total $(\mathrm{mmol} / \mathrm{l})$ & 66 & $2.66(2.46-3.09)$ & $2.20-2.55$ & 57 [i] \\
\hline P-Calcium alb. adj. (mmol/l) & 66 & $2.69(2.54-3.16)$ & $2.20-2.52$ & 66 [i] \\
\hline P-Creatinine $(\mu \mathrm{mol} / \mathrm{l})$ & 66 & $70(38-132)$ & $44-115$ & 1 [d], 1 [i] \\
\hline P-PTH (pmol/l) & 66 & $5.3(2.5-20.8)$ & $1.6-6.9$ & 15 [i] \\
\hline P-Phosphate (mmol/l) & 66 & $0.90(0.49-1.39)$ & $0.80-1.50$ & $16[d]$ \\
\hline P-25OHD (nmol/l) & 66 & $57(18-154)$ & $18-110^{\mathrm{a}}$ & $6[i]$ \\
\hline Summer (April-Sept) & 26 & $74.5(35-154)$ & $43-110^{a}$ & 2 [d], 3 [i] \\
\hline Winter (Oct-March) & 40 & $50(18-127)$ & $18-85^{a}$ & $4[\mathrm{i}]$ \\
\hline $\mathrm{P}-1,25(\mathrm{OH})_{2} \mathrm{D}(\mathrm{pmol} / \mathrm{l})$ & 66 & $126(56-307)$ & $39-220^{a}$ & $2[i]$ \\
\hline Creatinine clearance $(\mathrm{ml} / \mathrm{min})$ & 56 & $108(51-194)$ & $70-140$ & 4 [d], 8 [i] \\
\hline 24H-U-Calcium (mmol) & 56 & $2.7(0.7-9.5)$ & & \\
\hline 0 & 17 & $2.9(1.1-7.1)$ & o: $2.0-9.0$ & $3[\mathrm{~d}], 0[\mathrm{i}]$ \\
\hline$q$ & 39 & $2.6(0.7-9.5)$ & \%: $2.0-7.0$ & $10[\mathrm{~d}], 3[\mathrm{i}]$ \\
\hline Calcium/creatinine clearance ratio & 56 & $0.006(0.002-0.026)$ & - & \\
\hline
\end{tabular}

[i] Increased values. [d] Decreased values.

a Reference values are based on 46 healthy controls matched to $\mathrm{FHH}$ patients with respect to age ( \pm 5 years), sex, and season, and collected during summer $(N=21)$ and winter $(N=25)$ periods. 


\section{FHH patients: determinants of vitamin $D$ metabolites and PTH}

Table 2 summarizes correlations of vitamin D metabolites and PTH in FHH with other clinical variables using adjusted multiple regression analysis (partial correlation coefficients) after adjustment for age, sex, and BMI.

Plasma PTH showed positive partial correlations with plasma levels of total calcium $\left(r_{\mathrm{p}}=0.30, P=0.02\right)$, albumin-adjusted calcium $\left(r_{\mathrm{p}}=0.39, P<0.01\right), \mathrm{Ca}^{2+}$ $\left(r_{\mathrm{p}}=0.34, P<0.01\right)$, and creatinine $\left(r_{\mathrm{p}}=0.34, P<0.01\right)$, and correlated inversely with creatinine clearance rate $\left(r_{\mathrm{p}}=-0.47, P<0.02\right)$. Contrary to the findings in PHPT, plasma PTH was not related to plasma $250 \mathrm{HD}$ in $\mathrm{FHH}$ (Fig. 1). Moreover, PTH was not related to age, sex, plasma $25 \mathrm{OHD}$, and phosphate in a backward model $(N=66)$ that also included BMI $\left(r_{\mathrm{p}}=0.33, P<0.01\right), \mathrm{Ca}^{2+}$ $\left(r_{\mathrm{p}}=0.46, P<0.01\right)$, creatinine $\left(r_{\mathrm{p}}=0.46, P<0.01\right)$, and $1,25(\mathrm{OH})_{2} \mathrm{D}\left(r_{\mathrm{p}}=0.31, P=0.02\right)$.

Plasma $250 H D$ varied significantly $(P<0.01)$ with season with the highest levels during summer (Fig. 2). Following adjustment for sex, age, and BMI, there was a trend toward inverse correlations to the plasma calcium variables and positive correlations to plasma levels of phosphate and creatinine (Table 2). Plasma 250HD did not correlate with the renal 24-h calcium excretion or CCCR.

Plasma $1,25(\mathrm{OH})_{2} \mathrm{D}$ showed no seasonal variation. Following adjustment for sex, age, and BMI, it showed no correlation to other biochemical variables (Table 2). However, in a backward model also including plasma levels of $\mathrm{Ca}^{2+}$, creatinine, PTH, and phosphate, the plasma $1,25(\mathrm{OH})_{2} \mathrm{D}$ correlated inversely to plasma $\mathrm{Ca}^{2+}$ $\left(r_{\mathrm{p}}=-0.29, P=0.02\right)$ and positively to plasma PTH $\left(r_{\mathrm{p}}=0.28, P=0.02\right)$ with a trend toward an inverse correlation with plasma creatinine $\left(r_{\mathrm{p}}=-0.23, P=0.07\right)$.

Phenotypic expression of CASR mutation (as expressed by the degree of hypercalcemia): Fig. 3 shows plasma $1,25(\mathrm{OH})_{2} \mathrm{D}$ levels in the 14 different
CASR mutations included in this paper. $1,25(\mathrm{OH})_{2} \mathrm{D}$ shows no significant inter-mutation variation (one-way ANOVA, $P=0.96)$. We have previously demonstrated that plasma levels of PTH (one-way ANOVA, $P<0.01$ ) and plasma $\mathrm{Ca}^{2+}$ (one-way ANOVA, $P<0.01$ ) differ significantly between the different mutations (5).

\section{Differences between FHH and PHPT}

Table 3 compares descriptive and biochemical variables between $\mathrm{FHH}$ and PHPT patients. The FHH patients were younger, taller, and had a lower body weight than the PHPT patients. Plasma $\mathrm{Ca}^{2+}$ levels were identical, but total and albumin-adjusted calcium levels were slightly higher in the PHPT patients. PHPT patients had higher plasma creatinine levels and lower renal clearance rates than the $\mathrm{FHH}$ patients. Plasma PTH was increased by two- to threefold in the PHPT patients. Only 15 out of the $66 \mathrm{FHH}$ patients $(23 \%)$ had elevated plasma PTH compared with 133 out of the 147 PHPT patients $(90 \%), 2 p<0.01$. As to be expected, the $\mathrm{FHH}$ group had a significantly lower average urinary calcium excretion and CCCR than the PHPT patients.

We found no difference in plasma 250HD between the two groups, but the PHPT patients had 36\% higher average $\mathrm{P}-1,25(\mathrm{OH})_{2} \mathrm{D}$ levels than the $\mathrm{FHH}$ patients $(2 p<0.01)$. Adjustment for age, sex, BMI, season (summer/winter), and plasma levels of creatinine, phosphate and PTH did not change these findings.

\section{Discussion}

The present study demonstrates that average plasma $250 H D$ levels are normal, and average plasma $1,25(\mathrm{OH})_{2} \mathrm{D}$ levels increased in the matched $\mathrm{FHH}$ group $(N=46)$ compared with population based sex-, age-, and season-matched normal controls. Matching is

Table 2 Adjusted multiple regression analysis (partial correlation coefficients) of relationship between plasma levels of 25-hydroxyvitamin $\mathrm{D}(25 \mathrm{OHD}), 1,25$-dihydroxyvitamin $\mathrm{D}\left(1,25(\mathrm{OH})_{2} \mathrm{D}\right)$, or parathyroid hormone $(\mathrm{PTH})$ as the dependent variable and biochemical variables in patients with familial hypocalciuric hypercalcemia $(\mathrm{FHH})$. Model: dependent variable, age, sex, $\mathrm{BMI}$, and one other independent variable.

\begin{tabular}{|c|c|c|c|c|c|c|c|}
\hline \multirow[b]{3}{*}{ FHH } & \multicolumn{3}{|c|}{ 25OHD } & \multicolumn{2}{|c|}{$1,25(\mathrm{OH})_{2} \mathrm{D}$} & \multicolumn{2}{|c|}{ PTH } \\
\hline & \multicolumn{3}{|c|}{$\begin{array}{c}\text { Adjusted for age, sex, } \\
\text { and BMI }\end{array}$} & \multicolumn{2}{|c|}{$\begin{array}{c}\text { Adjusted for age, sex, } \\
\text { and BMI }\end{array}$} & \multicolumn{2}{|c|}{$\begin{array}{c}\text { Adjusted for age, sex } \\
\text { and BMI }\end{array}$} \\
\hline & $N$ & $r_{\mathrm{p}}$ & $P$ & $r_{\mathrm{p}}$ & $P$ & $r_{\mathrm{p}}$ & $P$ \\
\hline P-Calcium ionized (mmol/l) & 66 & -0.23 & 0.08 & -0.11 & 0.40 & 0.34 & $<0.01$ \\
\hline P-Calcium total $(\mathrm{mmol} / \mathrm{l})$ & 66 & -0.26 & 0.04 & -0.13 & 0.31 & 0.30 & 0.02 \\
\hline P-Calcium alb. adj. (mmol/l) & 66 & -0.20 & 0.11 & -0.08 & 0.54 & 0.39 & $<0.01$ \\
\hline P-Creatinine $(\mu \mathrm{mol} / \mathrm{l})$ & 66 & 0.23 & 0.07 & -0.05 & 0.71 & 0.34 & $<0.01$ \\
\hline P-PTH (pmol/l) & 66 & -0.06 & 0.67 & 0.20 & 0.12 & - & - \\
\hline P-Phosphate (mmol/l) & 66 & 0.24 & 0.06 & -0.06 & 0.63 & -0.21 & 0.10 \\
\hline $25 \mathrm{OHD}(\mathrm{nmol} / \mathrm{l})$ & 66 & - & - & 0.16 & 0.22 & -0.06 & 0.67 \\
\hline $1,25(\mathrm{OH})_{2} \mathrm{D}(\mathrm{pmol} / \mathrm{l})$ & 66 & 0.16 & 0.22 & - & - & 0.20 & 0.12 \\
\hline Creatinine clearance $(\mathrm{ml} / \mathrm{min})$ & 56 & 0.02 & 0.88 & 0.004 & 0.98 & -0.47 & $<0.01$ \\
\hline $24 \mathrm{H}-\mathrm{U}-\mathrm{Calcium}$ (mmol) & 56 & 0.18 & 0.20 & 0.18 & 0.20 & 0.11 & 0.43 \\
\hline Calcium/creatinine clearance ratio & 56 & 0.16 & 0.25 & 0.20 & 0.16 & 0.23 & 0.10 \\
\hline
\end{tabular}



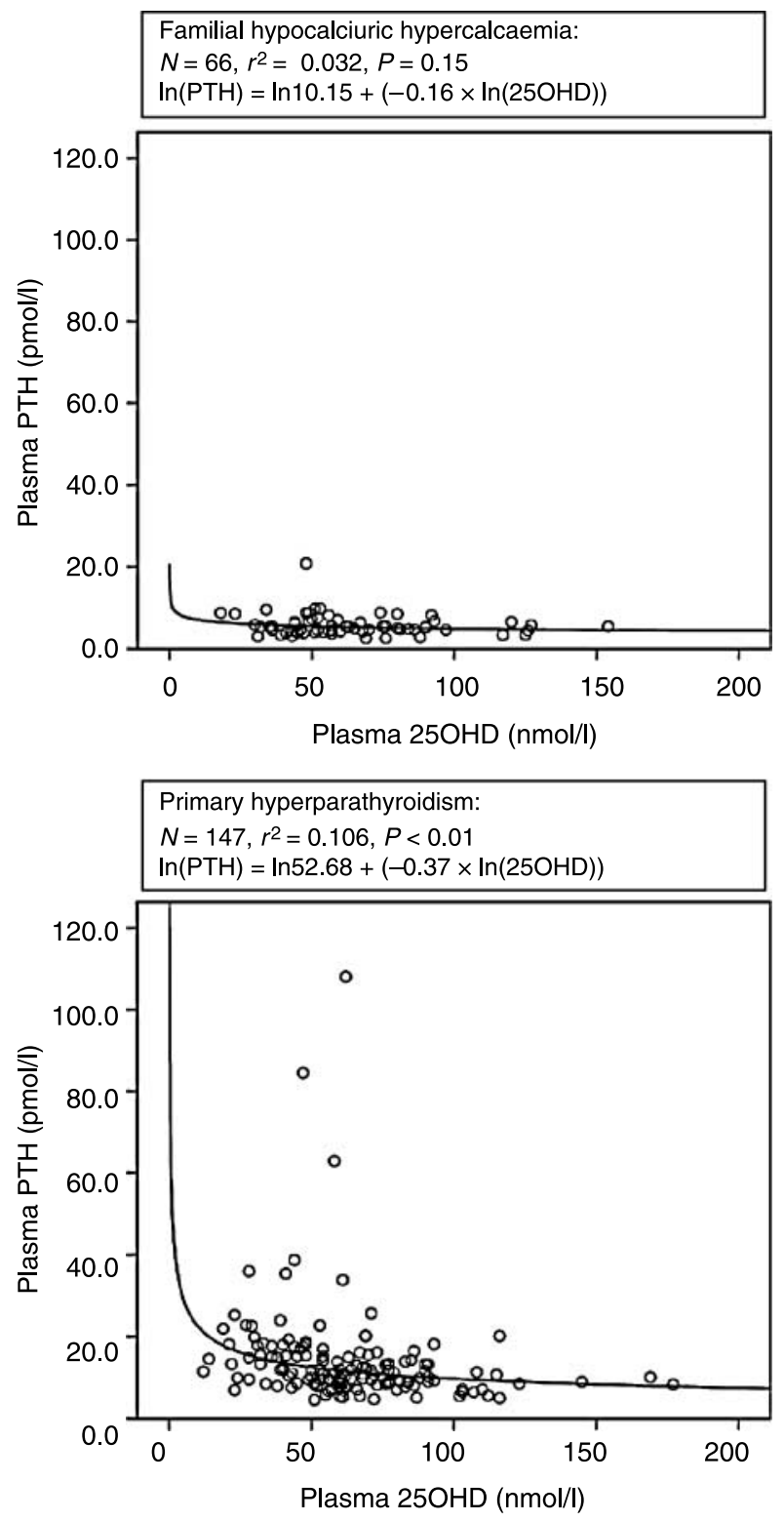

Figure 1 Plasma PTH versus plasma 25OHD in familial hypocalciuric hypercalcemia $(\mathrm{FHH})$ and primary hyperparathyroidism (PHPT). Curve estimation model: power transformation.

a way to reduce bias caused by known confounders. The non-matched FHH patients were 11 men, 4 pre-, and 5 postmenopausal women. They did not differ significantly from the matched patients in age, height, weight, BMI, plasma PTH, phosphate, calcium measurements, season, or vitamin D metabolites, but they had significantly higher plasma creatinine levels $(2 p<0.01)$ compared with the matched FHH patients.

With respect to $250 \mathrm{HD}$, our results are in accordance with a previous small Danish study performed between September 1982 and February 1983 (19). It included only ten FHH patients from one family and ten normal controls matched for age and sex and comparable

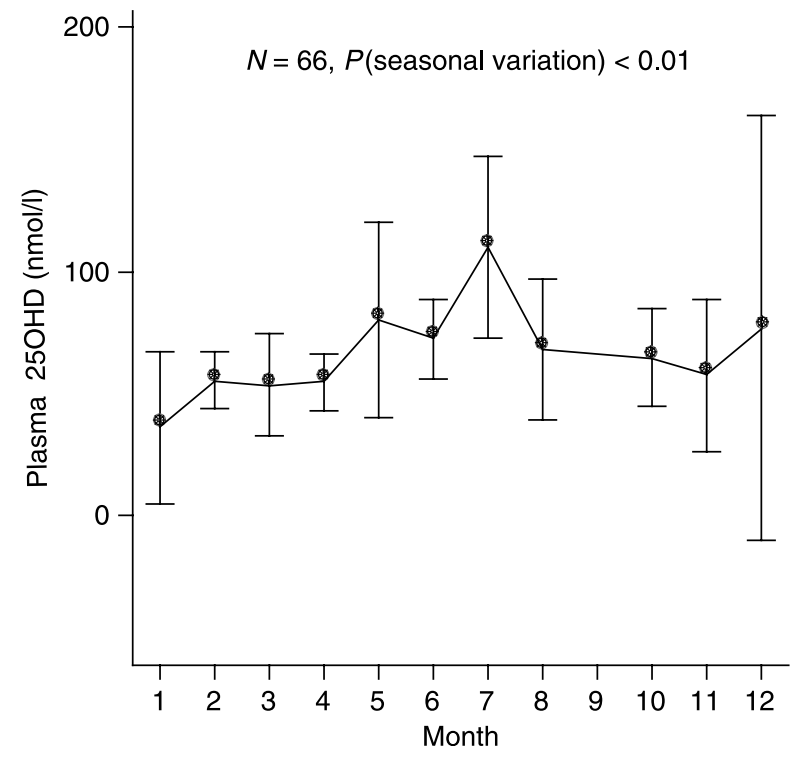

Figure 2 Seasonal variation in plasma $250 \mathrm{HD} \mathrm{nmol} / \mathrm{l}$ based on single measurements in 66 patients with familial hypocalciuric hypercalcemia $(\mathrm{FHH}$; mean $\pm 95 \% \mathrm{Cl})$.

regarding weight and body surface. Also, Law et al. found comparable $250 \mathrm{HD}$ levels in $32 \mathrm{FHH}$ patients and 65 normal controls $(18,22)$. Unfortunately, these data were not adjusted for season and BMI. In contrast to our study, Kristiansen et al. (19) were unable to detect any differences in $1,25(\mathrm{OH})_{2} \mathrm{D}$ levels between $\mathrm{FHH}$ patients and normal controls, but this could be due to the small number of individuals investigated.

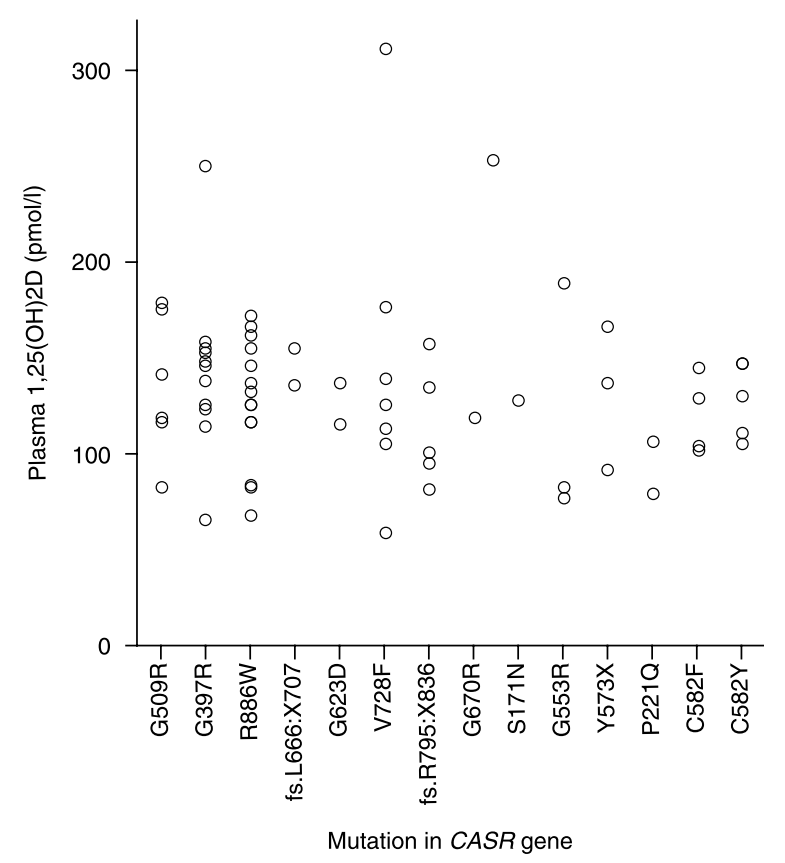

Figure 3 Scatterplot depicting the relationship between the CASR mutations and $1,25(\mathrm{OH})_{2} \mathrm{D}(5)$. 
Table 3 Comparison of descriptive and biochemical variables between patients with familial hypocalciuric hypercalcemia (FHH) and primary hyperparathyroidism (PHPT).

\begin{tabular}{|c|c|c|c|c|c|}
\hline & \multicolumn{2}{|c|}{ FHH } & \multicolumn{2}{|c|}{ PHPT } & \multirow[b]{2}{*}{$2 p$} \\
\hline & $N$ & Mean (S.D.) or \% & $N$ & Mean (S.D.) or \% & \\
\hline Age (years) & 66 & $51(16.1)$ & 147 & $60(14.4)$ & $<0.01$ \\
\hline Females $(\%)^{a}$ & 66 & 66.7 & & 78.9 & 0.06 \\
\hline Height $(m)^{b}$ & 66 & $1.69(0.09)$ & 136 & $1.66(0.09)$ & 0.02 \\
\hline Body weight $(\mathrm{kg})^{\mathrm{b}}$ & 66 & $70.5(15.1)$ & 143 & $75.6(17.0)$ & 0.04 \\
\hline BMI $\left(\mathrm{kg} / \mathrm{m}^{2}\right)^{\mathrm{b}}$ & 66 & $24.5(4.0)$ & 135 & $27.3(5.4)$ & $<0.01$ \\
\hline P-Calcium ionized $(\mathrm{mmol} / \mathrm{l})^{\mathrm{b}}$ & 66 & $1.44(0.10)$ & 140 & $1.46(0.12)$ & 0.32 \\
\hline P-Calcium total $(\mathrm{mmol} / \mathrm{l})^{\mathrm{b}}$ & 66 & $2.70(0.15)$ & 141 & $2.77(0.21)$ & 0.02 \\
\hline P-Calcium alb. adj. $(\mathrm{mmol} / \mathrm{l})^{\mathrm{b}}$ & 66 & $2.75(0.16)$ & 147 & $2.80(0.19)$ & 0.04 \\
\hline P-Creatinine $(\mu \mathrm{mol} / /)^{\mathrm{b}}$ & 66 & $73(15.6)$ & 147 & $79(14.7)$ & $<0.01$ \\
\hline P-PTH $(\mathrm{pmol} / /)^{\mathrm{b}}$ & 66 & $5.8(2.65)$ & 147 & $14.1(12.23)$ & $<0.01$ \\
\hline P-Phosphate $(\mathrm{mmol} / \mathrm{l})$ & 66 & $0.92(0.19)$ & 135 & $0.87(0.18)$ & 0.04 \\
\hline $\mathrm{P}-25 \mathrm{OHD}(\mathrm{nmol} / \mathrm{l})^{\mathrm{b}}$ & 66 & $64(27.6)$ & 147 & $63(27.4)$ & 0.69 \\
\hline $\mathrm{P}-1,25(\mathrm{OH})_{2} \mathrm{D}(\mathrm{pmol} / \mathrm{l})^{\mathrm{b}}$ & 66 & $127(40.5)$ & 113 & $173(64.6)$ & $<0.01$ \\
\hline Creatinine clearance $(\mathrm{ml} / \mathrm{min})$ & 56 & $109(28.3)$ & 128 & $93(33.8)$ & $<0.01$ \\
\hline $24 \mathrm{H}-\mathrm{U}-$ Calcium $(\mathrm{mmol})^{\mathrm{b}}$ & 56 & $3.3(2.03)$ & 129 & $8.2(4.36)$ & $<0.01$ \\
\hline Calcium/creatinine clearance ratio ${ }^{\mathrm{b}}$ & 56 & $0.008(0.006)$ & 117 & $0.23(0.009)$ & $<0.01$ \\
\hline
\end{tabular}

${ }^{\text {a } F i s h e r ' s ~ e x a c t ~ t e s t . ~}$

${ }^{\mathrm{b}}$ t-test based on logarithmic transformation of values.

The lack of reduction in plasma 250HD in the hypercalcemic FHH patients compared with normal individuals support the view that either plasma $\mathrm{Ca}^{2+}$ per se does not affect dermal vitamin D production or the effect is neutralized by the inactivating mutation in the CASR gene i.e., the reduced sensitivity toward hypercalcemia. It probably also means that the effect of the increased average plasma $1,25(\mathrm{OH})_{2} \mathrm{D}$ levels on the renal 24-hydroxylase is limited in these patients. However, the levels of $250 \mathrm{HD}$ depend largely on individual life style and this may mask the possible effect of $1,25(\mathrm{OH})_{2} \mathrm{D}$ on 24-hydroxylase activity. The borderline significant variation in $25 \mathrm{OHD}$ levels (oneway ANOVA, $P=0.06$ ) in the CASR mutations included in this study supports the possibility that plasma $\mathrm{Ca}^{2+}$ directly or indirectly may affect plasma $250 \mathrm{HD}$.

We have also disclosed that plasma 250HD shows seasonal variations in FHH. This is in accordance with the findings in normal Danish individuals (33), in Danish lactating women (34), and in Danish patients with PHPT (6). In the latter study, plasma 250HD covariated with monthly sun hours and satellite-based estimation of monthly UV exposure.

It is noteworthy that plasma levels of $250 \mathrm{HD}$ in our study were unrelated to the renal 24-h calcium excretion and to the CCCR. It has previously been shown that in PHPT patients, the renal calcium excretion is positively related to plasma $250 \mathrm{HD}$ even when adjusted by age, sex, BMI, creatinine, and season (6). The present finding could imply that vitamin D status and its effect on intestinal calcium absorption is of minor importance for the renal calcium excretion in FHH patients compared with the influence of the different CASR mutations. The lack of association between 250HD, renal 24-h calcium excretion and CCCR in FHH also supports the idea that individual vitamin D status is of limited importance for the use of CCCR as a diagnostic tool.

The increase in plasma $1,25(\mathrm{OH})_{2} \mathrm{D}$ compared with controls was positively related to plasma PTH and inversely to plasma $\mathrm{Ca}^{2+}$ and plasma creatinine. This is in accordance with the stimulatory effects of PTH on the renal $1 \alpha$-hydroxylase and the inhibitory effects of hypercalcemia and reduced renal function $(9,35-38)$. The inverse correlation with plasma $\mathrm{Ca}^{2+}$ after adjustment for plasma PTH in the model suggests that plasma $\mathrm{Ca}^{2+}$ still may suppress the renal $1 \alpha$-hydroxylase in spite of the inactivating mutations in the CASR. We could not demonstrate any effect of phosphate on $1,25(\mathrm{OH})_{2} \mathrm{D}$ concentrations in our FHH patients, although hypophosphatemia also is thought to enhance the $1 \alpha$-hydroxylase (9). Overall, changes in $1,25(\mathrm{OH})_{2} \mathrm{D}$ levels were limited and mainly took place within the normal reference range. This is in accordance with our finding that plasma $1,25(\mathrm{OH})_{2} \mathrm{D}$ did not depend on the different CASR mutations observed in the study.

In FHH, 23\% of patients had elevated plasma PTH that correlated positively to plasma calcium and inversely to creatinine clearance. The usually observed inverse hyperbolic relationship between $250 \mathrm{HD}$ and plasma PTH $(33,34,39,40)$ could not be retrieved in the present $\mathrm{FHH}$ population in contrast to the findings in the PHPT population. Other studies support that PTH varies inversely with vitamin D status in PHPT patients $(6,8)$. One explanation could be that the main cause of raised PTH levels in FHH is the inactivating mutation in the CASR and not secondary hyperparathyroidism provoked by vitamin D deficiency. This is supported by the significantly different effects of various CASR mutations on plasma PTH and plasma $\mathrm{Ca}^{2+}$ levels (5). Another explanation could be the lack of power due to the limited number of patients investigated. 
Our comparison of FHH and PHPT patients disclosed that despite similar levels of plasma $\mathrm{Ca}^{2+}$, the patients with PHPT had higher PTH levels, lower plasma phosphate, and higher $1,25(\mathrm{OH})_{2} \mathrm{D}$ in spite of slightly reduced renal function. The lack of difference in plasma $250 H D$ supports the study by Law et al. $(18,22)$, who found comparable $250 \mathrm{HD}$ levels but significantly higher levels of $1,25(\mathrm{OH})_{2} \mathrm{D}$ in $11 \mathrm{PHPT}$ patients compared with $32 \mathrm{FHH}$ patients. Davies et al. (17) also found increased $1,25(\mathrm{OH})_{2} \mathrm{D}$ levels in 14 PHPT patients compared with $14 \mathrm{FHH}$ patients after matching for serum calcium, creatinine clearance rate, and $250 \mathrm{HD}$. The higher $1,25(\mathrm{OH})_{2} \mathrm{D}$ levels in PHPT may be explained by the higher plasma PTH levels and the more reduced plasma phosphate levels in PHPT compared with $\mathrm{FHH}$ patients, since both variables stimulate the renal $1 \alpha$-hydroxylase $(9,10)$.

In the clinical setting, the separation between $\mathrm{FHH}$ and PHPT is often based on the CCCR $(20,41,42)$. We recommend a two-step diagnostic procedure in hypercalcemic patients with clinical suspicion of PHPT or FHH. The first step should be a CCCR determination with a cutoff value of $<0.020$. This will exclude around two out of three of the PHPT patients and sample $98 \%$ FHH patients (20). The next step should be a CASR gene analysis in the sampled group, separating those with significant mutations (FHH) from those without (PHPT) (20).

\section{Limitations to study}

The strength of the present study is the uniform, routine diagnostic program applied in all cases. The most important weakness is probably the omission of CASR gene studies in the PHPT patients. However, all PHPT patients remained normocalcemic 2 months after surgery and none of them have been readmitted for recurrent hypercalcemia and most of them had adenoma, not hyperplasia as seen in some cases of FHH (43).

We used different vitamin $\mathrm{D}$ assays for patients and normal controls due to the time lag between sampling. However, we have tried to address this question by adjusting the measurements in the normal controls to be equivalent to the measurements in the two patient groups. The equations used for these corrections were based on double measurements in 123 patients for $25 \mathrm{OHD}$ and in 74 patients for $1,25(\mathrm{OH})_{2} \mathrm{D}$ (32). The large material used for correction makes it unlikely that the differences in laboratory methods will cause sizeable differences in measured values after correction.

Molecular genetic analysis is unable to detect large rearrangements in the CASR gene, and may therefore neglect some cases of FHH (5). Locus heterogeneity may also exist (44). It is at present unknown whether $\mathrm{FHH}$ could be a risk factor for later development of PHPT, so that the two diseases, in rare cases, may occur together $(45,46)$. In the present study, it is unlikely that some participants had a combination of FHH and PHPT. First, all patients classified as having PHPT were normocalcemic 2 months after successful parathyroidectomy with a positive histological finding. Secondly, coexisting parathyroid adenoma was excluded by neck ultrasound and SPECT and planar parathyroid $\left({ }^{99 \mathrm{~m}} \mathrm{Tc}-\right.$ Sestamibi) and thyroid scintigraphy in the mutation positive $\mathrm{FHH}$ index patients and by neck ultrasound in all hypercalcemic relatives. In PHPT patients, both ultrasound and parathyroid scintigraphy have previously been shown to have positive predictive values above $80 \%$ for correctly localized adenomas. When both techniques were positive, the positive predictive value rose to $97 \%$ (47). We consider imaging to be a safe and non-invasive way of evaluating the status of the parathyroid glands.

\section{Conclusion}

Compared with normal controls, FHH patients have elevated plasma $1,25(\mathrm{OH})_{2} \mathrm{D}$ and unchanged plasma $250 H D$ levels. However, patients with $\mathrm{FHH}$ had lower plasma levels of $1,25(\mathrm{OH})_{2} \mathrm{D}$ and PTH, but comparable plasma levels of $\mathrm{Ca}^{2+}$ and $25 \mathrm{OHD}$ compared with PHPT patients.

\section{Declaration of interest}

The authors declare that there is no conflict of interest that could be perceived as prejudicing the impartiality of the research reported.

\section{Funding}

This research did not receive any specific grant from any funding agency in the public, commercial, or not-for-profit sector.

\section{Acknowledgements}

The authors wish to express their gratitude to Mrs Ulla Fahrenholtz and Mrs Helle Thøgersen for their remarkable and professional secretarial assistance; Mrs Tove S Stenum and Mrs Lisbeth Flyvbjerg for their extraordinary laboratory work and valuable discussions; Ms Edith Clausen, our efficient research librarian, for her outstanding helpfulness and for retrieving references.

\section{References}

1 Hendy GN, D’Souza-Li L, Yang B, Canaff L \& Cole DEC. Mutations of the calcium-sensing receptor (CASR) in familial hypocalciuric hypercalcemia, neonatal severe hyperparathyroidism, and autosomal dominant hypocalcemia. Human Mutation $2000 \mathbf{1 6}$ 281-296.

2 Thakker RV. Diseases associated with the extracellular calciumsensing receptor. Cell Calcium 200435 275-282.

3 Brown EM \& MacLeod RJ. Extracellular calcium sensing and extracellular calcium signaling. Physiological Reviews 200181 239-297.

4 Pidasheva S, D’Souza-Li L, Canaff L, Cole DE \& Hendy GN. CASRdb: calcium-sensing receptor locus-specific database for mutations causing familial (benign) hypocalciuric hypercalcemia, neonatal severe hyperparathyroidism, and autosomal dominant hypocalcemia. Human Mutation 200424 107-111. 
5 Nissen PH, Christensen SE, Heickendorff L, Brixen K \& Mosekilde L. Molecular genetic analysis of the calcium sensing receptor gene in patients clinically suspected to have familial hypocalciuric hypercalcemia: phenotypic variation and mutation spectrum in a Danish population. Journal of Clinical Endocrinology and Metabolism 200792 4373-4379.

6 Moosgaard B, Vestergaard P, Heickendorff L, Melsen F, Christiansen P \& Mosekilde L. Vitamin D status, seasonal variations, parathyroid adenoma weight and bone mineral density in primary hyperparathyroidism. Clinical Endocrinology 200563 506-513.

7 Moosgaard B, Vestergaard P, Heickendorff L \& Mosekilde L. Plasma 1,25-dihydroxyvitamin D levels in primary hyperparathyroidism depend on sex, body mass index, plasma phosphate and renal function. Clinical Endocrinology 200766 35-42.

8 Silverberg SJ, Shane E, Dempster DW \& Bilezikian JP. The effects of vitamin D insufficiency in patients with primary hyperparathyroidism. American Journal of Medicine 1999107 561-567.

9 Brown AJ, Dusso A \& Slatopolsky E. Vitamin D. American Journal of Physiology 1999277 F157-F175.

10 Dusso AS, Brown AJ \& Slatopolsky E. Vitamin D. American Journal of Physiology. Renal Physiology 2005 289 F8-F28.

11 Yamashita H, Yamashita T, Miyamoto M, Shigematsu T, Kazama JJ, Shimada T, Yamazaki Y, Fukumoto S, Fukagaw M \& Noguchi S. Fibroblast growth factor (FGF)-23 in patients with primary hyperparathyroidism. European Journal of Endocrinology $200415155-60$.

12 Kobayashi K, Imanishi Y, Miyauchi A, Onoda N, Kawata T, Tahara H, Goto H, Miki T, Ishimura E, Sugimoto T, Ishikawa T, Inaba M \& Nishizawa Y. Regulation of plasma fibroblast growth factor 23 by calcium in primary hyperparathyroidism. European Journal of Endocrinology 2006154 93-99.

13 Sauer B, Ruwisch L \& Kleuser B. Antiapoptotic action of $1 \alpha$, 25-dihydroxyvitamin D3 in primary human melanocytes. Melanoma Research 200313 339-347.

14 Hosoi J, Abe E, Suda T \& Kuroki T. Regulation of melanin synthesis of B16 mouse melanoma cells by 1 $\alpha, 25$-dihydroxyvitamin D 3 and retinoic acid. Cancer Research 198545 1474-1478.

15 Bolland MJ, Grey AB, Gamble GD \& Reid IR. Association between primary hyperparathyroidism and increased body weight: a metaanalysis. Journal of Clinical Endocrinology and Metabolism 200590 1525-1530.

16 Snijder MB, van Dam RM, Visser M, Deeg DJ, Dekker JM, Bouter LM, Seidell JC \& Lips P. Adiposity in relation to vitamin D status and parathyroid hormone levels: a population-based study in older men and women. Journal of Clinical Endocrinology and Metabolism $2005904119-4123$.

17 Davies M, Adams PH, Berry JL, Lumb GA, Klimiuk PS, Mawer EB \& Wain D. Familial hypocalciuric hypercalcemia - observations on vitamin-D metabolism and parathyroid function. Acta Endocrinologica $1983104210-215$.

18 Law WM Jr, Bollman S, Kumar R \& Heath H III. Vitamin D metabolism in familial benign hypercalcemia (hypocalciuric hypercalcemia) differs from that in primary hyperparathyroidism. Journal of Clinical Endocrinology and Metabolism 198458 744-747.

19 Kristiansen JH, Rodbro P, Christiansen C, Mortensen JB \& Carl J. Familial hypocalciuric hypercalcemia. 2. Intestinal calciumabsorption and vitamin-D metabolism. Clinical Endocrinology 198523 511-515.

20 Christensen SE, Nissen PH, Vestergaard P, Heickendorff L, Brixen K \& Mosekilde L. Discriminative power of three indices of renal calcium excretion for the distinction between familial hypocalciuric hypercalcaemia and primary hyperparathyroidism: a follow-up study on methods. Clinical Endocrinology, 2008 (DOI: 10.1111/j.13652265.2008.03259).

21 Marx SJ, Spiegel AM, Brown EM, Koehler JO, Gardner DG, Brennan MF \& Aurbach GD. Divalent cation metabolism. Familial hypocalciuric hypercalcemia versus typical primary hyperparathyroidism. American Journal of Medicine 197865 235-242.

22 Law WM \& Heath H. Familial benign hypercalcemia (hypocalciuric hypercalcemia) - clinical and pathogenetic studies in 21 families. Annals of Internal Medicine 1985102 511-519.
23 Heath DA. Familial hypocalciuric hypercalcemia. Reviews in Endocrine and Metabolic Disorders 20001 291-296.

24 Glendenning P. Diagnosis of primary hyperparathyroidism: controversies, practical issues and the need for Australian guidelines. Internal Medicine Journal 200333 598-603.

25 Bussey AD \& Bruder JM. Urinary calcium excretion in primary hyperparathyroidism: relationship to 25-hydroxyvitamin D status. Endocrine Practice 200511 37-42.

26 Tfelt-Hansen J \& Brown EM. The calcium-sensing receptor in hereditary disorders of calcium homeostasis. Clinical Cases in Mineral and Bone Metabolism 20063 150-161.

27 Souberbielle JC, Cormier C, Kindermans C, Gao P, Cantor T, Forette F \& Baulieu EE. Vitamin D status and redefining serum parathyroid hormone reference range in the elderly. Journal of Clinical Endocrinology and Metabolism 200186 3086-3090.

28 Souberbielle JC, Lawson-Body E, Hammadi B, Sarfati E, Kahan A \& Cormier C. The use in clinical practice of parathyroid hormone normative values established in vitamin D-sufficient subjects. Journal of Clinical Endocrinology and Metabolism 200388 3501-3504.

29 Rejnmark L, Vestergaard P, Heickendorff L, Andreasen F \& Mosekilde L. Effects of thiazide- and loop-diuretics, alone or in combination, on calcitropic hormones and biochemical bone markers: a randomized controlled study. Journal of Internal Medicine 2001250 144-153.

30 Rejnmark L, Jorgensen ME, Pedersen MB, Hansen JC, Heickendorff L, Lauridsen AL, Mulvad G, Siggaard C, Skjoldborg H, Sorensen TB, Pedersen EB \& Mosekilde L. Vitamin D insufficiency in Greenlanders on a westernized fare: ethnic differences in calcitropic hormones between Greenlanders and Danes. Calcified Tissue International 2004 74 255-263.

31 Rejnmark L, Vestergaard P, Heickendorff L, Andreasen F \& Mosekilde L. Effects of long-term treatment with loop diuretics on bone mineral density, calcitropic hormones and bone turnover. Journal of Internal Medicine 2005257 176-184.

32 Moosgaard B, Christensen SE, Vestergaard P, Heickendorff L, Christiansen P \& Mosekilde L. Vitamin D metabolites and skeletal consequences in primary hyperparathyroidism. Clinical Endocrinology $2008 \mathbf{6 8} 707-715$.

33 Brot C, Vestergaard P, Kolthoff N, Gram J, Hermann AP \& Sorensen OH. Vitamin D status and its adequacy in healthy Danish perimenopausal women: relationships to dietary intake, sun exposure and serum parathyroid hormone. British Journal of Nutrition 200186 (Suppl 1) S97-S103.

34 Moller UK, Ramlau-Hansen CH, Rejnmark L, Heickendorff L, Henriksen TB \& Mosekilde L. Postpartum vitamin D insufficiency and secondary hyperparathyroidism in healthy Danish women. European Journal of Clinical Nutrition $2006 \mathbf{6 0} 1214-1221$.

35 Zierold C, Mings JA \& Deluca HF. Regulation of 25-hydroxyvitamin D-3-24-hydroxylase mRNA by 1,25-dihydroxyvitamin D-3 and parathyroid hormone. Journal of Cellular Biochemistry $2003 \mathbf{8 8}$ 234-237.

36 Wu SX, Finch J, Zhong M, Slatopolsky E, Grieff M \& Brown AJ. Expression of the renal 25-hydroxyvitamin D-24-hydroxylase gene: regulation by dietary phosphate. American Journal of Physiology. Renal Physiology 199640 F203-F208.

37 Mawer EB, Taylor CM, Backhouse J, Lumb GA \& Stanbury SW. Failure of formation of 1,25-dihydroxycholecalciferol in chronic renal insufficiency. Lancet 19731 626-628.

38 Mosekilde L, Charles P \& Lindegreen P. Determinants for serum 1,25-dihydroxycholecalciferol in primary hyperparathyroidism. Bone and Mineral 19895 279-290.

39 Lips P. Vitamin D deficiency and secondary hyperparathyroidism in the elderly: consequences for bone loss and fractures and therapeutic implications. Endocrine Reviews 200122 477-501.

40 Mosekilde L. Vitamin D and the elderly. Clinical Endocrinology 2005 62 265-281.

41 Gunn IR \& Gaffney D. Clinical and laboratory features of calciumsensing receptor disorders: a systematic review. Annals of Clinical Biochemistry 200441 441-458.

42 Bilezikian JP, Potts JT Jr, Fuleihan GE-H, Kleerekoper M, Neer R, Peacock M, Rastad J, Silverberg SJ, Udelsman R \& Wells SA. 
Summary Statement from a Workshop on asymptomatic primary hyperparathyroidism: a perspective for the 21st Century. Journal of Clinical Endocrinology and Metabolism $2002 \mathbf{8 7}$ 5353-5361.

43 Marx SJ, Spiegel AM, Brown EM \& Aurbach GD. Family studies in patients with primary parathyroid hyperplasia. American Journal of Medicine 197762 698-706.

44 Lloyd SE, Pannett AAJ, Dixon PH, Whyte MP \& Thakker RV. Localization of familial benign hypercalcemia, Oklahoma variant (FBHOk), to chromosome 19q13. American Journal of Human Genetics 199964 189-195.

45 Burski K, Torjussen B, Paulsen AQ, Boman H \& Bollerslev J. Parathyroid adenoma in a subject with familial hypocalciuric hypercalcemia: coincidence or causality? Journal of Clinical Endocrinology and Metabolism 200287 1015-1016.
46 Carling T, Szabo E, Bai M, Ridefelt P, Westin G, Gustavsson P, Trivedi S, Hellman P, Brown EM, Dahl N \& Rastad J. Familial hypercalcemia and hypercalciuria caused by a novel mutation in the cytoplasmic tail of the calcium receptor. Journal of Clinical Endocrinology and Metabolism 200085 2042-2047.

47 Rasmussen K, Larsen LP, Arveschoug A, Theil NJ, Vestergaard P, Ronning H, Mosekilde L \& Christiansen P. Predictive value of parathyroid scintigraphy in the preoperative evaluation of patients with primary hyperparathyroidism. Scandinavian Journal of Surgery 200695 199-204.

Received 3 July 2008

Accepted 23 August 2008 